\title{
The Design of Infusion Monitoring System based on STM32 Microcontroller
}

\author{
XU Zhihui, LI Weizhong, XIAO Yongjun* \\ HuBei Engineering University \\ School of Physics and Electronic Information Engineering \\ Xiaogan, China \\ E-mail: 75694676@qq.com
}

\begin{abstract}
- conventional manual adjustment to control the drop speed in clinical infusion has more unadvantageous and cannot realize automatic controlling and monitoring of the infusion speed. According to this condition, the infusion monitoring system is designed based on the STM32 microcontroller and one pair of infrared emitting and receiving diode, and the experimental is done. The result shows that this designed monitoring system can reach high accuracy, high reliability and low adjust time.
\end{abstract}

Keywords-infusion monitoring system; STM32F103; infrared emitting and receiving diode

\section{INTRODUCTION (HEADING 1)}

Intravenous infusion dispensation is widely used in clinical treatment, However, Manual adjustment to control drop speed with the character of inadequate accuracy, inconvenience, infusion abnormal and end is difficult to find, is usually adopted in most hospital over many decades and maybe cause medical malpractice ${ }^{[1][2][3][4][5]}$. In recent years, the more attention of researchers is pay on the automatic infusion system ${ }^{[6][7][8][9]}$.

According to current research condition, the infusion monitoring system is designed in this paper. In the first section, the hardware design of the infusion monitoring system is detailed, and the block diagram of the whole system is also discussed. In the second section, the software flow chart of the infusion monitoring system is designed. In the last section, the experiment is done and some conclusions are derived from the experiment data.

\section{THE HARDWARE DESIGN OF THE INFUSION MONITORING SYSTEM}

The whole block diagram of the infusion monitoring system is illustrated in figure 1 . This system with the control core of STM32F103 microcontroller, can realize the measurement and controlling of drop speed. The whole system is consisted of control module, step motor and its driver, sheave, infusion bottles and infusion monitoring sensor. The infusion bottles can be pull up or down by step motor to adjust the infusion speed, while the infusion monitoring sensor can real-time measure the drop speed and the sped signal is sent to microcontroller after the process of signal shaper.

The expand keyboard of the STM32F103 is used for the input of preset speed or other command, LCD module is used for the real-time display of drop speed and infusion residual quantity. The ADC module, as the Peripheral of STM32F103, is in charge of conversion from analog to digital. The PWM signal, produced by the PWM module, is sent to step motor driver and drive the motor to rotate. The infusion speed sensor, adopted in this system, is one pairs of the infrared emitting and receiving diode.

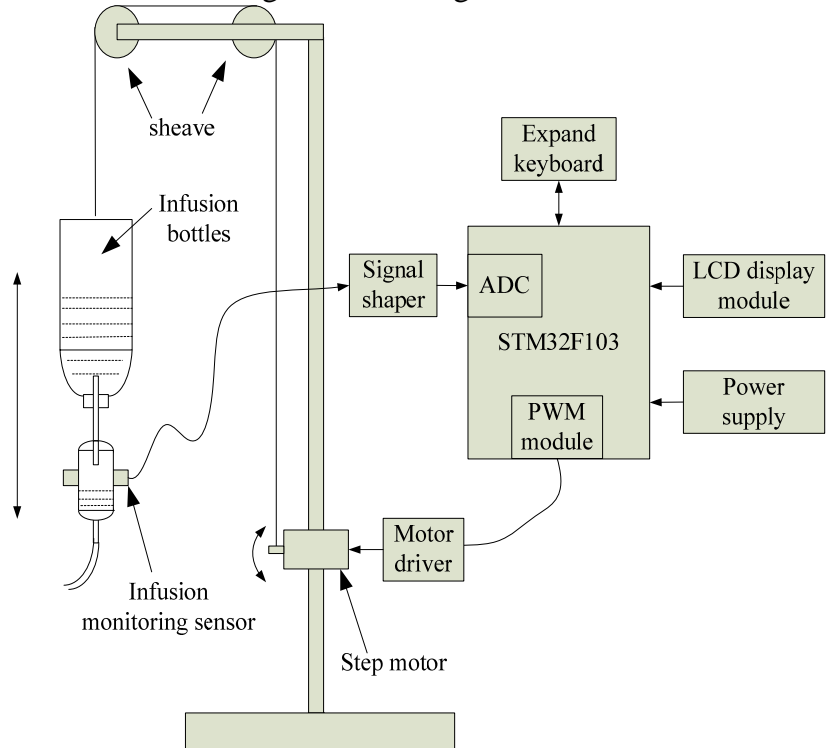

Figure 1 block diagram of the infusion monitoring system

A. The description of STM32 microcontroller ${ }^{[10][11]}$

The STM32F103 family incorporates the highperformance ARM ${ }^{\circledR}$ Cortex ${ }^{\mathrm{TM}}$-M3 32-bit RISC core operating at a $72 \mathrm{MHz}$ frequency, high-speed embedded memories (Flash memory up to 512 Kbytes and SRAM up to 64 Kbytes), and an extensive range of enhanced I/Os and peripherals connected to two APB buses. All devices offer three 12-bit ADCs, four general purpose 16-bit timers plus two PWM timers, as well as standard and advanced communication interfaces: up to two I2Cs, three SPIs, two I2Ss, one SDIO, five USARTs, an USB and a CAN. It is suitable for a wide range of applications: motor drive and application control, PC peripherals gaming and GPS platforms.

\section{B. Designs for sensor signal shaper}

The schematic circuit of the sensor signal shaper is shown in figure 2 . It is consisted of a two order low pass filter, one inverting amplifier and two inverting gates. The 
two order low pass filter is adopted to remove the noise of inputted sensor signal, and the more pure signal is sent to next circuit. The inverting amplifier is in charge of the amplification of the input signal. The last two inverting gates are used for the shaping of inputted pulse signals.

In this circuit, sensor signal of the infusion drop speed is inputted from two order low pass filter, then amplified by the inverting amplifier, passed through two inverting gates, and outputted to STM32 microcontroller.

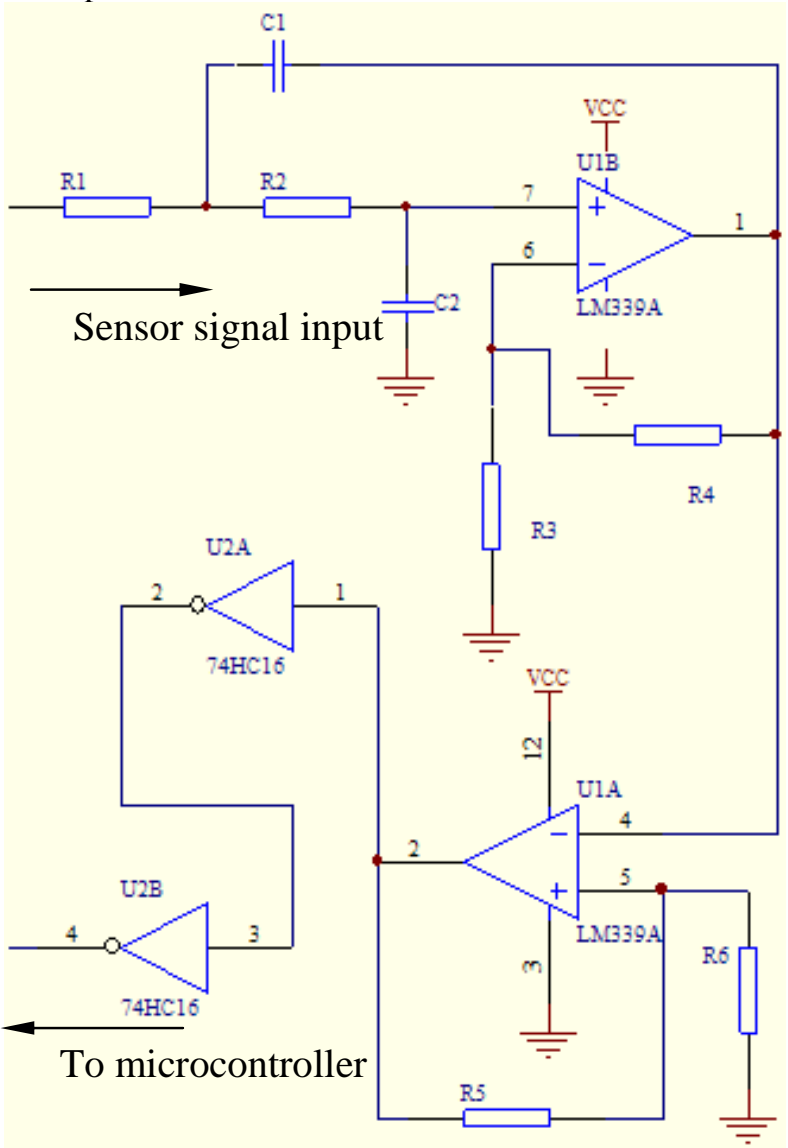

Figure 2 Schematic circuit of the sensor signal shaper

C. The connection between motor and the driver

A stepper motor is an electro-mechanical-device which converts electrical pulses into discrete mechanical movements and widely used in industry application. Consider the convenient to use, the step motor driver DMD402 is adopted in this system, and the connection of microcontroller, motor driver and step motor is shown in figure 3 . The microcontroller should provide four signals: motor enable signal, rotating direction signal, PWM pulse and $+5 \mathrm{v}$ power. The power supply of the DMD402 is $+24 \mathrm{~V}$ $\mathrm{DC}$, and can driver the step motor with four signals: A+, A-, $\mathrm{B}+$ and $\mathrm{B}-$.

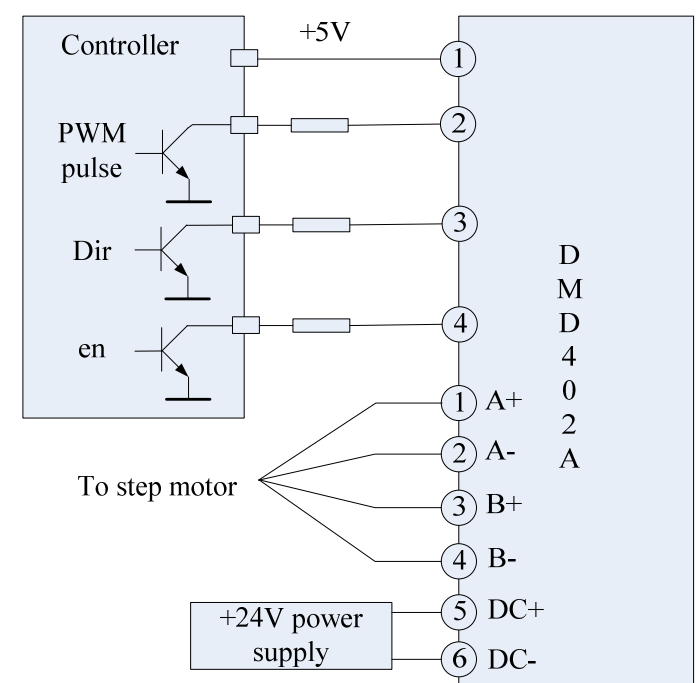

Figure 3 the connection of microcontroller, motor driver and step motor

III. THE SOFTWARE DESIGN OF THE INFUSION MONITORING SYSTEM

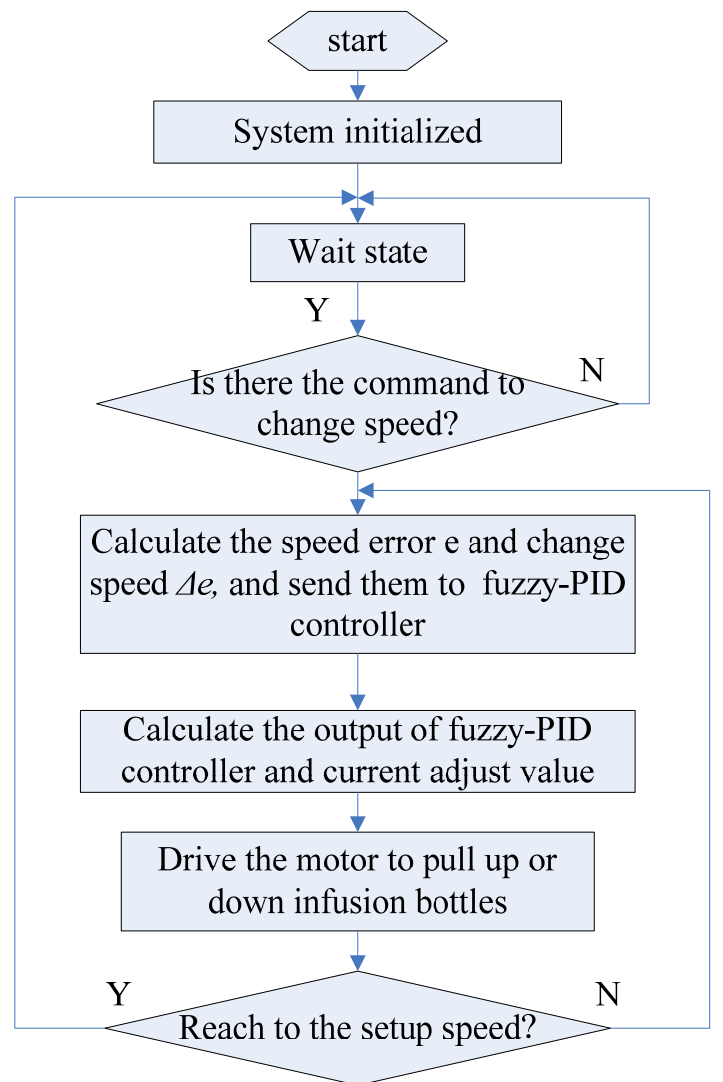

Figure 4 the flow chart of the system software

The flow chart of the system software is illustrated in figure 4 . When the power supply is switched on, the system will enter into initial state, and then enter into wait state. If the infusion drops speed is set, the system will soon collect the current drop speed and calculates the speed error $e$. If 
the speed error is the allowable error, the system enter again into the wait state; otherwise, the change speed of error $\Delta e$ is also calculated out. Both the speed error $e$ and the change speed of error $\Delta e$ are sent to fuzzy-PID controller ${ }^{[12][13][14]}$ ${ }^{[15]}{ }^{[16]}$, and then the current adjust value is calculated out. The PWM pulse is produced by STM32 microcontroller according to the current adjust value, and sent to step motor driver to drive the motor to pull the infusion bottles up or down. After waiting for a moment, the adjustment is ended and if the current speed error is within the allowable error, the system will be enter again into wait state, otherwise, it will be adjusted again.

\section{EXPERIMENT AND DATA ANALYSIS}

Table 1 experimental result for infusion speed

\begin{tabular}{|c|c|c|c|}
\hline $\begin{array}{c}\text { Initial } \\
\text { speed } \\
\text { (drops per } \\
\text { minute) }\end{array}$ & $\begin{array}{c}\text { preset } \\
\text { speed } \\
\text { (drops per } \\
\text { minute) }\end{array}$ & $\begin{array}{c}\text { Adjusted } \\
\text { speed } \\
\text { (drops per } \\
\text { minute) }\end{array}$ & $\begin{array}{c}\text { Adjust } \\
\text { time } \\
\text { (second) }\end{array}$ \\
\hline 20 & 40 & 38 & 121 \\
\hline 38 & 60 & 62 & 125 \\
\hline 62 & 80 & 79 & 123 \\
\hline 79 & 100 & 97 & 117 \\
\hline 97 & 120 & 118 & 120 \\
\hline 118 & 140 & 141 & 122 \\
\hline
\end{tabular}

At last, the experiment of monitoring and controlling for the infusion drops speed is done based on the designed system, and the experimental result is shown in table 1 . We change the drop speed every 20 drops, the adjusted speed is near the preset speed and within the two drops per minute. The adjusted time is almost same for different infusion speed.

From the table, we can derive the conclusion that this designed monitoring system can reach high accuracy, high reliability and low adjust time.

\section{CONCLUSIONS}

The system of monitoring and controlling of infusion drop speed is designed based on the STM32 microcontroller and the infrared emitting and receiving diode as the drops speed sensor is adopted. In this system, the adjustment of drops speed is finished by the pull-up or -down of the infusion bottles. The experiment is done based on this system, and the result shows that this designed monitoring system can reach high accuracy, high reliability and low adjust time.

This infusion monitoring system can be widely used in monitoring and management in the course of the infusion to advance the working conditions of medical staffs and reduce the medical errors in the small hospitals.

\section{ACKNOWLEDGMENT}

We would like to express our thanks to ours students for their valuable discussions and helps to improve this paper and ready for our experiment.

\section{REFERENCES}

[1] Derrick JL, Ho AM, Cho AM. Consequences of syringe size sensor malfunction in a modern infusion pump[J], Anaesthesia and intensive care, 2003, V. 31 no. $1: 75-79$

[2] Neff TA, Fischer JE, Schulz G, Baenziger O, Weiss M. Infusion pump performance with vertical displacement : effect of syringe pump and assembly type[J]. Intensive care medicine, V27, no. 1, $2001: 287-291$

[3] Schroeder, ME Wolman, RL Wetterneck, TB Carayon, P. Tubing misload allows free flow event with smart intravenous infusion pump[J]. Anesthesiology, 2006, v01. 105 no. 2 : 434435

[4] K K Thariyan, Sanjeev Verma, S R Taneja, R C Gupta, S S Ahluwalia. Design and Development of a Unique Drop Sensing Unit for Infusion Pump[J]. Journal of Scientific \& Industrial Research, 2002, V01. 61 No. $10: 798-801$

[5] SHAN Wei. Design and implementation of the infusion monitoring system based on AT89S52 [D]. HeFei: HeFei University of technology, 2009 (in chinese)

[6] Ting Jiang, Chengli. Technology and application of ZigBee[J]. Beijing University of Post and Telecommunication, 2006

[7] HUO Lifeng. Research and implement of the distributed infusion control/monitoring system [D]. TaiYuan: TaiYuan University of technology, 2007 (in chinese)

[8] Wenju YANG, Lihua SUN. A Novel Medical Infusion Monitoring System Based on ZigBee Wireless Sensor Network[J]. Proceedings of the 2009 International Symposium on Web Information Systems and Applications (WISA’09), pp 291-293

[9] Shi Zhuan, "Zigbee based wireless sensor network and its application in industrial”, Proceeding of the IEEE International conference on automation and logisties, pp. 18-21, August, 2009

[10] ST Microelectronics. RM0008 Reference manual (Medium-and High-density STM32F101xx and STM32F103xx advanced ARMbased 32-bit MCUs). 2008

[11] ARM Limited. Cortex-M3 Technical Reference Manual. 2005

[12] Daniel E. Rivera , Manfred Morari , Sigurd Skogestad. Internal model control: PID controller design[J]. Ind. Eng. Chem. Process Des. Dev., 1986, 25 (1), pp 252-265

[13] SIRA-RAMIREZ,H. H1989I: "A geometric approach to pulse-width modulated control in nonlinear dynamical systems.” IEEE Transactions on Automatic Control, 35:12

[14] Wang Yan, fuzzy immune PID - type controller design and simulation, Computer Simulation, Vol 19, pp.67-69, February 2002 (In Chinese)

[15] Sun Yanfei, Zhang Shunyin, Rao Xiang, et al, the research of multimedia streams self-regulating algorithm based on fuzzy immune PID, Journal of Electronics \& Information Technology, Vol 27, pp.1651-1655, October 2005 (In Chinese)

[16] ZHOU Chuanlin, YANG Zhi, XIAO Yongjun, et al. Control System Design of Blushless DC motor Based on Personal Computer [J]. Journal of Wuhan Institute of Technology, 2011, 33(6):82-74, 106 (In Chinese) 